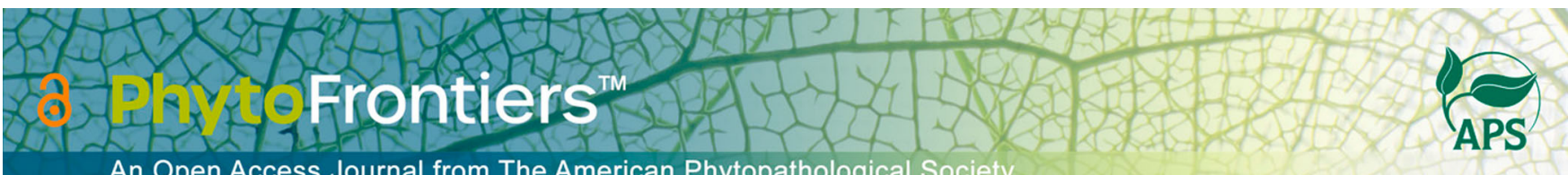

\title{
Research
}

\section{Correlating Light Absorbance Parameters in Peach Skin with Susceptibility to Streaking and Association with Rainwater Components}

\author{
Linus Thaddaeus Schmitz | G. Schnabel ${ }^{+}$(D) |
}

Department of Plant and Environmental Sciences, Clemson University, Clemson, SC 29634

† Corresponding author: G. Schnabel;
schnabe@clemson.edu

Accepted for publication 8 September 2021

Technical contribution no. 6992 of the Clemson University Experiment Station.

\section{Funding}

This material is based upon work supported by the South Carolina Peach Council, Southern Region SARE OS17-109, and NIFA/USDA project number SC-1700594.

The author(s) declare no conflict of interest.

\begin{abstract}
Since it was first observed in 2003, peach skin streaking (PSS) has increasingly affected fruit production in the southeastern United States. Since 2017 , we have documented the occurrence of PSS on 21 cultivars in South Carolina, and symptoms have also been reported in Maryland and Pennsylvania. PSS seems to be linked to an unidentified causal agent mediated in rainwater with susceptibility closely related to the ripening status of maturing fruit. Over the course of the 2019 peach growing season, we collected rainwater at a South Carolina peach farm with a history of PSS and analyzed samples for chemical and physical properties. Five cultivars were monitored for occurrence of PSS to associate specific rain events with symptom development in the field. PSS was observed in the field on one of the monitored and three additional cultivars between May and June, and five rain events coincided in time with symptom development. However, chemical and physical properties from these rainwater samples were not significantly different from samples not associated with PSS in that time frame. Fruit of the five cultivars was also collected at $21,14,7$, and 0 days before harvest to determine light absorbance parameters, $\Delta \mathrm{A}$, and color space and to induce symptoms under laboratory conditions by treatment with $\mathrm{ClO}_{2}$. Results indicate significant correlations between symptom development and light absorbance parameters, illustrating that proneness to PSS increases during fruit maturation.
\end{abstract}

Keywords: peach skin streaking, fruit maturation, fruit production, Prunus persica

Peach skin streaking (PSS) has become a significant issue for both conventional and organic growers in the southeastern United States. Fruit that is affected by this disorder may show epidermal symptoms in the form of chlorotic and sometimes necrotic streaks on the fruit finish (Fig. 1). Although the streaks impact the visual appearance of the fruit, other sensory attributes such as taste or texture appear to be unaffected. Nevertheless, the overall quality is diminished, and symptomatic fruit may be deemed unsuitable for 
wholesale and even for direct marketing. The occurrence of PSS is sporadic and therefore difficult to predict in time and place (Schmitz and Schnabel 2019). Unlike recurring fruit orchard pests and diseases, occurrence of PSS cannot be anticipated, and it is unknown whether there are differences in cultivar susceptibility.

The causes of PSS are still unknown, but symptoms resemble the gravitational flow of small droplets down the fruit skin, suggesting water, in the form of dew or rain, to be the carrier of the causal agent. Initially, it was hypothesized that atmospheric chemicals such as sulfuric acid $\left(\mathrm{H}_{2} \mathrm{SO}_{4}\right)$, nitric acid $\left(\mathrm{HNO}_{3}\right)$, and hydrochloric acid $(\mathrm{HCl})$ may concentrate in rainwater and damage color pigments in the peach skin. A previous study demonstrated that symptoms similar to those of PSS can be reproduced under both lab and field conditions using sodium hypochlorite $(\mathrm{NaClO})$ and chlorine dioxide $\left(\mathrm{ClO}_{2}\right)$ at $100 \mu \mathrm{g} / \mathrm{ml}$, respectively (Hu et al. 2017). However, analysis of rainwater from 12 commercial peach production sites revealed that levels of chlorine $\left(\mathrm{Cl}_{2}\right)$ and $\mathrm{ClO}_{2}$ do not exceed $0.1 \mu \mathrm{g} / \mathrm{ml}$ (Schmitz and Schnabel 2019).

Both studies have also shown that susceptibility to PSS may be dependent on both the ripening status of the peach fruit and the cultivar. It is therefore important to characterize the physiological state of the peach skin at different time points during maturation and correlate such indices to susceptibility.

Light absorbance parameters such as chlorophyll degradation and color space are used in fruit production to estimate time to harvest and to determine internal qualities such as sugar content and acidity (Bonora et al. 2013; Nyasordzi et al. 2013). The transition of peach skin color from green to yellow and red relates to the fruit's physiological status, whereas final blush is directly linked to nutritional value (Frett et al. 2014). The methods used to determine light absorbance parameters in this study allow for nondestructive sampling and thus for the same fruit to be used for subsequent susceptibility tests.

The objectives of this study were to establish a list of peach cultivars with documented susceptibility to PSS and to determine associations between streaking incidence and physical and

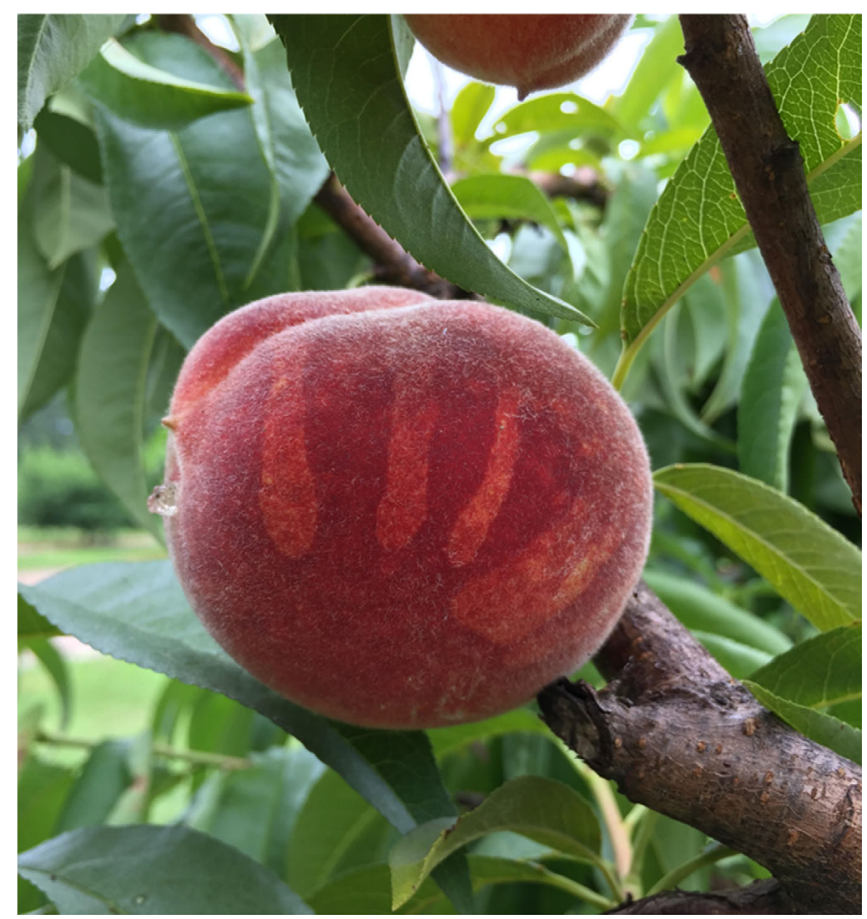

FIGURE 1

Symptoms of peach skin streaking on hanging fruit. chemical properties of rainwater, as well as light absorbance parameters of maturing fruit.

\section{MATERIALS AND METHODS}

\section{Rainwater analysis and streaking potential}

Rainwater was collected at the Musser Fruit Research Center (MFRC) in Seneca, SC $\left(34^{\circ} 36^{\prime} 11^{\prime \prime} \mathrm{N}, 82^{\circ} 52^{\prime} 43^{\prime \prime} \mathrm{W}\right)$ from early April to mid-July during the 2019 peach growing season. A system was designed to harvest only the initial $1.5 \mathrm{~mm}$ of precipitation while retrieving sample volumes sufficient for analysis. The system consisted of three components: a catchment area, conveyance, and storage/collection. A $2.3-\mathrm{m}^{2}$ industrial leak diverter (Uline, Pleasant Prairie, WI) was suspended from four fence posts to create a funnel-like catchment area. Rainwater would collect in the middle of the tarp and then drain into a standard 19-mm garden hose from where it was channeled to a PVC pipe $(10-\mathrm{cm} \varnothing, 50-\mathrm{cm}$ height). Inside the pipe was a first flush diverter (RainHarvest Systems LLC, Cumming, GA), which utilized a ball-and-seat system to seal off the chamber as the water level rose. This allowed for only collecting the first $1.5 \mathrm{~mm}$ of rain in which contaminants were most likely to be found. Any excess water was directed out of the pipe and into a polyethylene (PE) bin (7.5 liters, $24 \mathrm{~cm}$; Lowe's Companies, Mooresville, NC). A valve at the bottom of the pipe allowed the contents of the chamber to be emptied into another PE bin for sampling. Samples were collected in 500-ml PE bottles (SKS Bottle and Packaging, Watervliet, NY). The bottles were rinsed with the rainwater three times before being filled and capped under the water line in the bin. After sampling, the system was cleaned under running tap water and air dried. Three 500-ml aliquots were taken for subsequent analysis after each rainfall, which was monitored with the weather station onsite using the WeatherLink app (Davis Instruments, Hayward, CA). One aliquot was submitted to the Clemson Agricultural Service Laboratory for analysis within $24 \mathrm{~h}$ of sampling and refrigerated until submission when sampled on the weekend. The attributes determined were $\mathrm{pH}$, salinity, and sodium absorption ratio. The samples were also tested for phosphorus, potassium, calcium, magnesium, zinc, copper, manganese, iron, sodium, chloride, boron, sulfur, nitrate nitrogen, bicarbonate, and carbonate. Moreover, the rainwater samples were analyzed for heavy metals including aluminum, arsenic, cadmium, chromium, molybdenum, nickel, lead, and selenium.

The second 500-ml aliquot was stored in a cooler on ice until it was used the same day to inoculate detached fruit to investigate whether the rainwater would induce streaking symptoms under controlled conditions. Fruit used for this experiment included any cultivars readily available in the orchards on site and approximately 7 days away from commercial harvest, the most susceptible time for fruit to develop streaking. A volume of $300 \mu \mathrm{l}$ of rainwater was applied to the right and left side of the suture, respectively, starting from the shoulder of the stem, using a 1,000- $\mu$ l pipette (Eppendorf, Hamburg, Germany). A nonionic surfactant (Latron B-1956; BASF, Research Triangle, NC) was added at $0.125 \%$ to ensure that the rainwater stuck to the fruit to form a drip line resembling the characteristic streaking pattern. Fruit was incubated at room temperature on the lab bench in closed plastic boxes with a damp paper towel at the bottom and monitored for 5 days. The third 500-ml aliquot was stored at $-20^{\circ} \mathrm{C}$ as a reserve sample.

Over the course of the peach growing season, May to July, streaking incidence was monitored specifically on five cultivars ('Juneprince', 'Coronet', 'Scarletprince', 'Julyprince', and 
'Redglobe') and any cultivars approximately 7 days shy of commercial maturity following rain events. Instances of occurrence of symptoms coinciding with precipitation were noted.

\section{Light absorbance measurements and streaking susceptibility}

Fruit from the same five cultivars mentioned above were picked $21,14,7$, and 0 days before commercial maturity, respectively, to determine a possible relationship between fruit maturity and streaking susceptibility. Prior to generating streaking symptoms on detached fruit according to Schmitz and Schnabel (2019), fruit maturity parameters were quantified. For each cultivar and picking date, 15 fruits similar in size and color were selected, and two readings (left and right of the suture) were taken per fruit. Two nondestructive methods were chosen. Difference of absorbance between 670 and $720 \mathrm{~nm}$, which relates to the chlorophyll content in the mesocarp, was measured with a DA meter 53500 (T.R. Turoni Srl, Forli, Italy). The color or blush of experimental fruit was quantified using a Chroma meter CR400 (Konica Minolta, Tokyo, Japan) to measure L* (light intensity; $-\mathrm{L}^{*}$ : dark, $+\mathrm{L}^{*}$ : light), $\mathrm{a}^{*}\left(-\mathrm{a}^{*}\right.$ : green, $+\mathrm{a}^{*}$ : red), and $\mathrm{b}^{*}$ $\left(-\mathrm{b}^{*}\right.$ : blue, $+\mathrm{b}^{*}$ : yellow). The latter two, $\mathrm{a}^{*}(x)$ and $\mathrm{b}^{*}(y)$, were converted to polar coordinates to determine the saturation and the hue angle. After determining maturity, fruit was subjected to treatment with 500-ppm $\mathrm{ClO}_{2}$ as described previously to induce streaking symptoms (Schmitz and Schnabel 2019). Using the Aquamira Chlorine Dioxide Water Treatment kit (Aquamira Technologies, Logan, UT), equal amounts of solutions part A and part $\mathrm{B}$ were mixed for 5 to $10 \mathrm{~min}$ to generate $1 \%$ active $\mathrm{ClO}_{2}$, which was diluted to $0.05 \%(500 \mathrm{ug} / \mathrm{ml})$. A nonionic surfactant (Latron B-1956, BASF, Research Triangle, NC) was added at $0.125 \%$ to enhance retention of the treatment solution on the fruit surface. The number of symptomatic fruits was determined $48 \mathrm{~h}$ after treatment for each cultivar and sampling time.

\section{Statistical analysis}

All data were analyzed using JMP Pro version 14.3.0 (SAS Institute, Cary, NC). A Student $t$ test was used to compare rainwater properties between samples associated and not associated with streaking symptoms to determine possible differences. Oneway analysis of variance (ANOVA) was used to determine an effect of weeks before harvest on streaking susceptibility and light absorbance parameters. Means were separated based on Fisher's protected least square difference (with $P=0.05$ ). A simple linear regression model was fit to predict streaking susceptibility as a function of (i) difference of absorbance $\Delta \mathrm{A}$, (ii) light intensity $\mathrm{L}^{*}$, (iii) $\mathrm{a}^{*}$, and (iv) $\mathrm{b}^{*}$.

\section{RESULTS}

\section{Occurrence of peach skin streaking among cultivars and peach-producing states}

Over the course of 3 years (2017 to 2019), PSS was reported on 21 cultivars from commercial orchards in Saluda, Oconee, Edgefield, and Spartanburg counties of South Carolina and experimental orchards at the MFRC in Seneca, South Carolina (Table 1). PSS severity ranged from faint, light symptoms to severe symptoms, with most of the cultivars exhibiting light symptoms. Reports of streaking were also confirmed on cultivar White Lady in commercial farms in Maryland and Pennsylvania (Table 1). A distinct absence of streaking was recorded for cultivars August Lady, Blazeprince, Redskin, and September Sun (Table 1).

\section{Rainwater analysis}

Twenty water samples from rain events at the MFRC were collected during the 2019 peach growing season. The $\mathrm{pH}$ of

TABLE 1

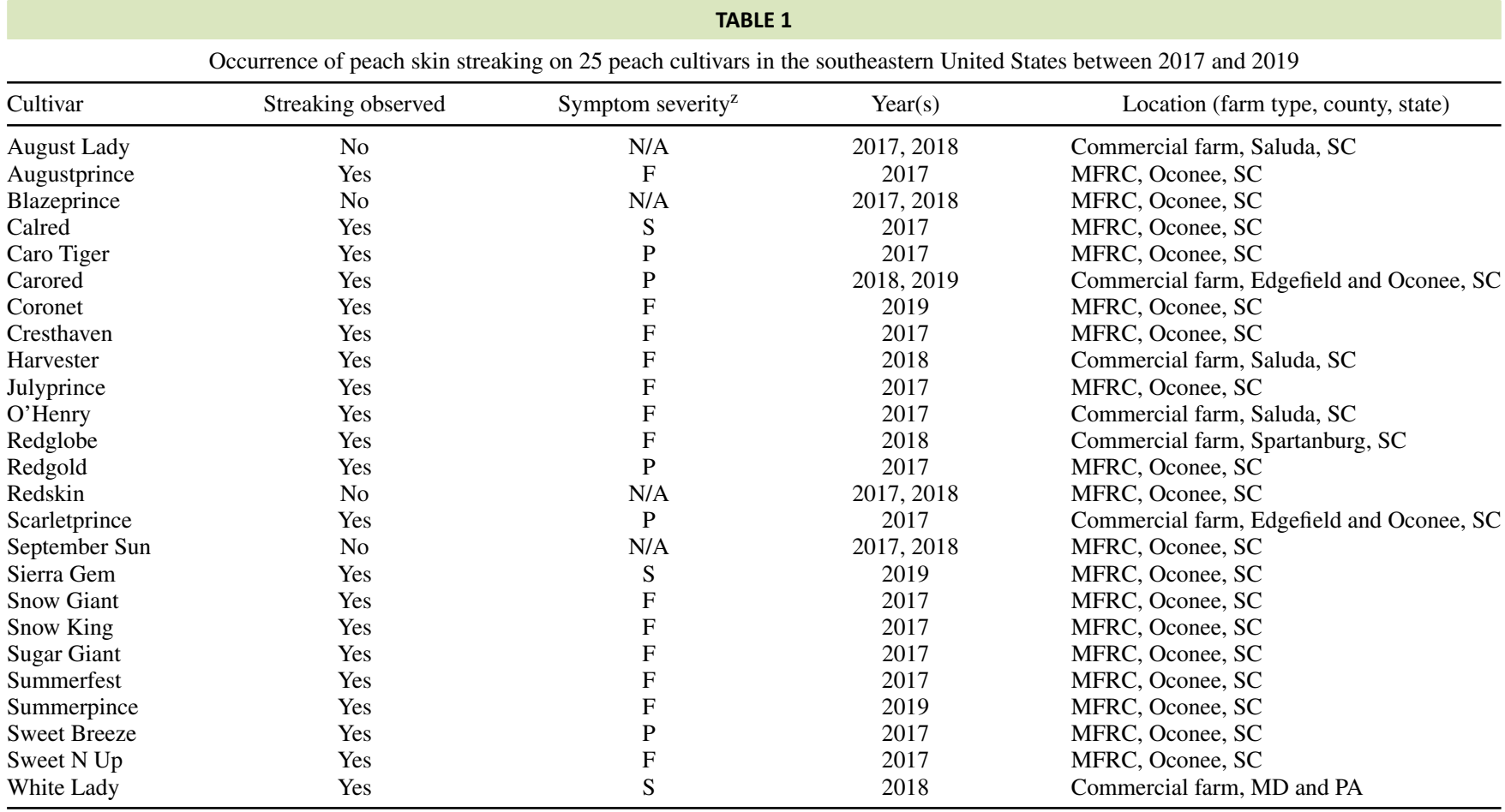

z Symptom severity: $\mathrm{F}=$ faint, light symptoms; $\mathrm{P}=$ pronounced symptoms with solid yellow streaks; and $\mathrm{S}=$ severe symptoms, necrotic streaks accompanied by sunken tissue. 
rainwater samples ranged from 5.7 to 7.4 , with an average of 6.55, and the electrical conductivity (EC) ranged from 0.01 and 0.12 (mean 0.03). Chloride $\left(\mathrm{Cl}^{-}\right)$levels ranged from 0 to $4.93 \mathrm{mg} / \mathrm{liter}$, with an average of $0.38 \mathrm{mg} / \mathrm{liter}$. Total dissolved salts and the sodium absorption ratio ranged from 6 to $77 \mathrm{mg} / \mathrm{liter}$ and 0.07 to $4.27 \mathrm{mg} / \mathrm{liter}$, respectively. Concentrations of heavy metals other than iron and zinc were consistently below the detection limit (data not shown).

\section{Association of rainwater with streaking}

Over the course of the peach growing season, five rain events $(\leq 15 \mathrm{~mm})$ between May and June were within 10 days of PSS occurrence at the MFRC. Symptoms were observed on May 22 on cultivar Carored $(<5 \%)$, on June 10 on cultivars Sierra Gem (no data) and Summerprince (33\%), and on June 18 on cultivar Coronet $(13 \%)$. Related rain events occurred on May 13 and 17 (1 mm and $13 \mathrm{~mm}$ ), and June 6, 7, and 10 (5, 21, and $15 \mathrm{~mm})$. Analysis of rainwater from these dates was compared to nine samples collected between May and July that were not associated (fell outside the 10-day window or were after symptom occurrence) with in-field streaking symptoms. Values for each component were compared between groups by one-way ANOVA. There were no significant differences for any rainwater attribute between samples associated and not associated with streaking (Table 2).

\section{Streaking susceptibility and light absorbance parameters during fruit maturation}

Fruit picked at weekly intervals starting 3 weeks before harvest differed significantly regarding streaking susceptibility and light absorbance parameters. Streaking susceptibility increased from 3 to 1 week before harvest but decreased the last week of harvest. Fruits picked 3 and 2 weeks before harvest were least susceptible, with 13 and $31 \%$ of fruit developing symptoms after $\mathrm{ClO}_{2}$ treatment, whereas $86 \%$ of fruit picked 1 week before harvest was symptomatic (Table 3 ). The difference of absorbance $\Delta \mathrm{A}$ decreased as fruit ripened, indicating an increasing degradation of chlorophyll in the mesocarp during fruit maturation. Similarly, $\mathrm{a}^{*}$ values increased from -12 at 3 weeks before harvest to 30 at harvest, illustrating the development of blush as the fruit ripens. Although there was no effect of picking time on the saturation of fruit finish, the hue angle was significantly lower at 3 weeks before harvest (Table 3 ).

Linear regression analysis was performed between streaking susceptibility of peach fruit and light absorbance parameters $\Delta \mathrm{A}$, $\mathrm{L}^{*}, \mathrm{a}^{*}$, and $\mathrm{b}^{*}(P<0.05$; Fig. 2$)$. Streaking susceptibility and difference of absorbance $\Delta \mathrm{A}$ were negatively correlated, with a correlation coefficient $r$ equal to 0.883 , suggesting that susceptibility increased as the chlorophyll content in the mesocarp decreased. Similarly, a positive correlation $(r=0.917)$ was estimated between susceptibility and $a^{*}$, implying that peach fruit was increasingly more susceptible with the onset of anthocyanin production. Blush intensity $\mathrm{L}^{*}$ and $\mathrm{b}^{*}$ were each found to be negatively correlated to streaking susceptibility $(r=0.7819$ and $r=0.7350$ ), again illustrating how peach fruit was more prone to symptom development as it matured (Fig. 2).

\section{DISCUSSION}

Most commercial cultivars are susceptible to PSS. We documented the occurrence of PSS on 23 popular cultivars grown in three southeastern states. Streaking incidence has been reported annually for at least 10 years in Edgefield and Saluda counties, where a large portion of South Carolina peaches are grown, but the economic impact is still unclear. PSS is a localized and sporadic event (Schmitz and Schnabel 2019), and popular cultivars such as Coronet, Julyprince, Augustprince, Scarletprince, Cresthaven, Harvester, and O'Henry, which represent a significant acreage for many growers, are susceptible. Although severe symptoms forming necrotic areas are less frequently observed, fruit finish is impaired by faint, light symptoms, reducing overall product quality and value. Additionally, consumers may associate streaking with pesticide damage, a perception that could lead them to not buy the product and may hurt brand recognition.

There was no component in rain samples that correlated with streaking incidence. This is consistent with previous findings (Schmitz and Schnabel 2019). However, that does not necessarily mean that rain attributes are not linked to streaking. Although samples were collected as soon as possible after rain events, the causal agent might only be stable in water for periods of time too short for collection and analysis. Gases such as ozone $\left(\mathrm{O}_{3}\right), \mathrm{ClO}_{2}$, or ammonia $\left(\mathrm{NH}_{3}\right)$ could accumulate in the troposphere and react with rain in sufficient concentration to affect peach fruit cells.

TABLE 2

Rainwater components in relation to their ability to cause streaking on peach fruit

\begin{tabular}{lccc}
\hline Component & $\begin{array}{c}\text { Mean value of rainwater } \\
\text { associated with streaking }(n=5)\end{array}$ & $\begin{array}{c}\text { Mean value of rainwater not } \\
\text { associated with streaking }(n=9)\end{array}$ & $P$ value \\
\hline Precipitation (mm) & 10.92 & 4.82 & 0.1672 \\
pH & 6.38 & 6.61 & 0.4999 \\
Electrical conductivity (mmhos/cm) & 0.02 & 29.78 & 0.1806 \\
Total dissolved salts (meq/liter) & 11.60 & 0.43 & 0.1865 \\
Sodium absorption ratio (meq/liter) & 0.18 & 0.22 & 0.0622 \\
Nitrate-N (mg/liter) & 0.40 & 0.05 & 0.5185 \\
Phosphorous (mg/liter) & 0.02 & 0.89 & 0.2500 \\
Potassium (mg/liter) & 0.42 & 0.86 & 0.3322 \\
Calcium (mg/liter) & 0.64 & 0.36 & 0.5231 \\
Sulfur (mg/liter) & 0.22 & 0.20 & 0.3317 \\
Magnesium (mg/liter) & 0.08 & 0.16 & 0.3915 \\
Iron (mg/liter) & 0.14 & 0.15 & 0.7335 \\
Chloride (mg/liter) & 0.12 & 0.16 & 0.8695 \\
Zinc (mg/liter) & 0.10 & 0.03 & 0.4831 \\
Copper (mg/liter) & 0.01 & 1.62 & 0.3636 \\
Sodium (mg/liter) & 0.47 & 0.29 & 0.1576 \\
Bicarbonate (meq/liter) & 0.12 & 0.24 & 0.3277 \\
Residual sodium carbonate (meq/liter) & 0.08 & & 0.3780 \\
\hline
\end{tabular}


During this interaction, symptoms may be induced, but the causal agent could be broken down to uninvestigated byproducts. Ozone readily dissolves in water but does not react with it at $\mathrm{pH}$ values below 7 (Gordon 1995). The $\mathrm{pH}$ values of rainwater samples collected in this study were 6.55 on average and only above 7 in two instances with $\mathrm{pH}$ of 7.3 and 7.4, respectively (data not shown).
Decomposition of $\mathrm{O}_{3}$ at elevated $\mathrm{pH}$, above 8, highly depends on the presence of other molecules and is also influenced by sunlight (Gordon 1995). Because rainwater was collected in a PVC tube until collection and $\mathrm{pH}$ values were below 7 on average, we assume that $\mathrm{O}_{3}$, if present, was stable in our samples. Ammonia also is very soluble in aqueous solution and forms ammonium

TABLE 3

Streaking susceptibility and light absorbance parameters of maturing fruit

\begin{tabular}{|c|c|c|c|c|c|c|c|}
\hline \multirow[b]{2}{*}{ Weeks before harvest } & \multirow[b]{2}{*}{ Streaking incidence $(\%)^{\mathrm{X}}$} & \multicolumn{6}{|c|}{ Light absorbance parameters ${ }^{\mathrm{w}}$} \\
\hline & & $\Delta \mathrm{A}$ & $\mathrm{L}^{*}$ & $\mathrm{a}^{*}$ & $b^{*}$ & $\mathrm{r}$ & $\Theta$ \\
\hline 0 & $58 \mathrm{~b}$ & $0.29 \mathrm{~d}$ & $48 \mathrm{c}$ & $30 \mathrm{a}$ & $30 \mathrm{c}$ & 42 & $58 \mathrm{a}$ \\
\hline 1 & $86 a$ & $0.75 \mathrm{c}$ & $56 \mathrm{~b}$ & $22 \mathrm{~b}$ & $36 \mathrm{~b}$ & 43 & $44 \mathrm{a}$ \\
\hline 2 & $31 \mathrm{c}$ & $1.48 \mathrm{~b}$ & $66 \mathrm{a}$ & $1 \mathrm{c}$ & $44 \mathrm{a}$ & 44 & $16 \mathrm{a}$ \\
\hline 3 & $13 \mathrm{c}$ & $1.94 \mathrm{a}$ & $66 \mathrm{a}$ & $-12 \mathrm{~d}$ & $43 \mathrm{a}$ & 44 & $-75 b$ \\
\hline $\operatorname{LSD}(P=0.05)^{\mathrm{y}}$ & 18 & 0.16 & 3 & 3 & 3 & & 44 \\
\hline One-way ANOVA; $P>F^{\mathrm{Z}}$ & $<0.0001$ & $<0.0001$ & $<0.0001$ & $<0.0001$ & $<0.0001$ & 0.6146 & 0.0017 \\
\hline
\end{tabular}

${ }^{\mathrm{w}}$ Light absorbance parameters: $\Delta \mathrm{A}=$ difference of absorbance, correlates to chlorophyll content in mesocarp; $\mathrm{L}^{*}=$ intensity, $-\mathrm{L}^{*}$ dark, $+\mathrm{L}^{*}$ light; $\mathrm{a}^{*}=-\mathrm{a}^{*}$ green, $+a^{*}$ red; $b^{*}=-b^{*}$ blue, $+b^{*}$ yellow; $r=$ saturation; and theta $(\Theta)=$ hue angle.

$x$ Streaking susceptibility was determined by subjecting detached fruit to $500 \mathrm{ppm} \mathrm{ClO}_{2}$ the day of harvest and recording the number of fruits that developed symptoms relative to the total number of fruits (Schmitz and Schnabel 2019).

y Least significant difference (LSD) values used to separate means within each column; calculated by multiplying the $t$ statistic with the standard error difference.

z $\mathrm{ANOVA}=$ analysis of variance; $P>F=$ probability of greater $F$ statistics occurring.

A

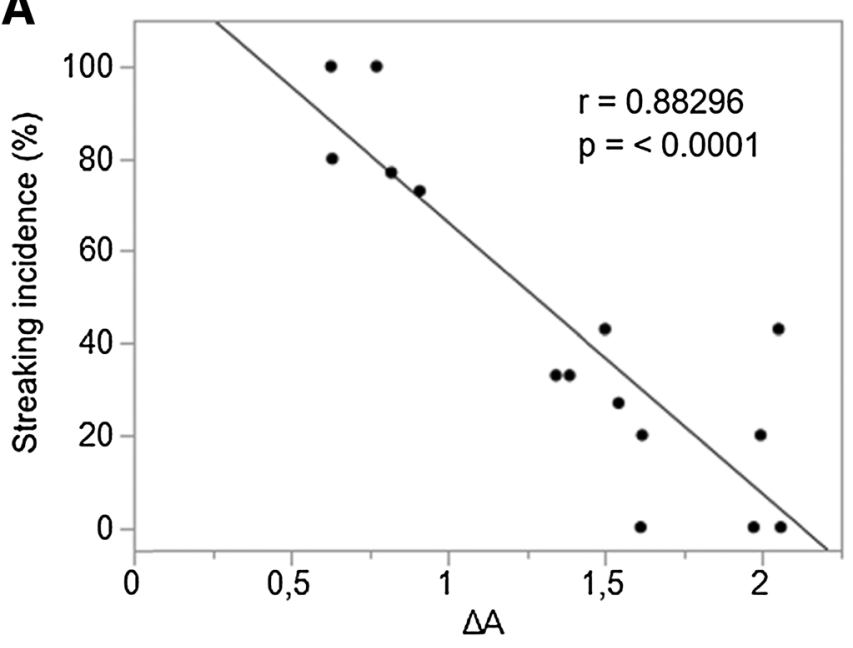

C

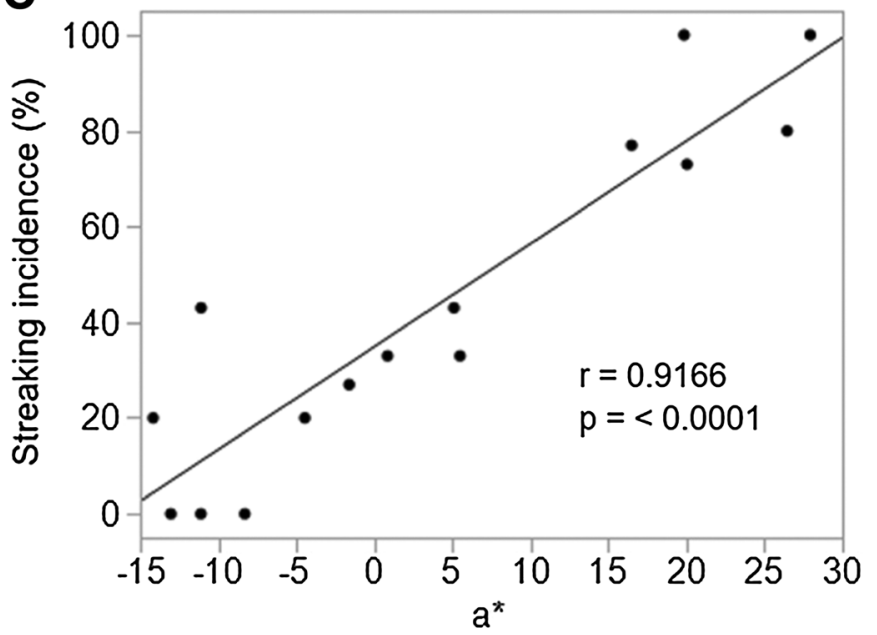

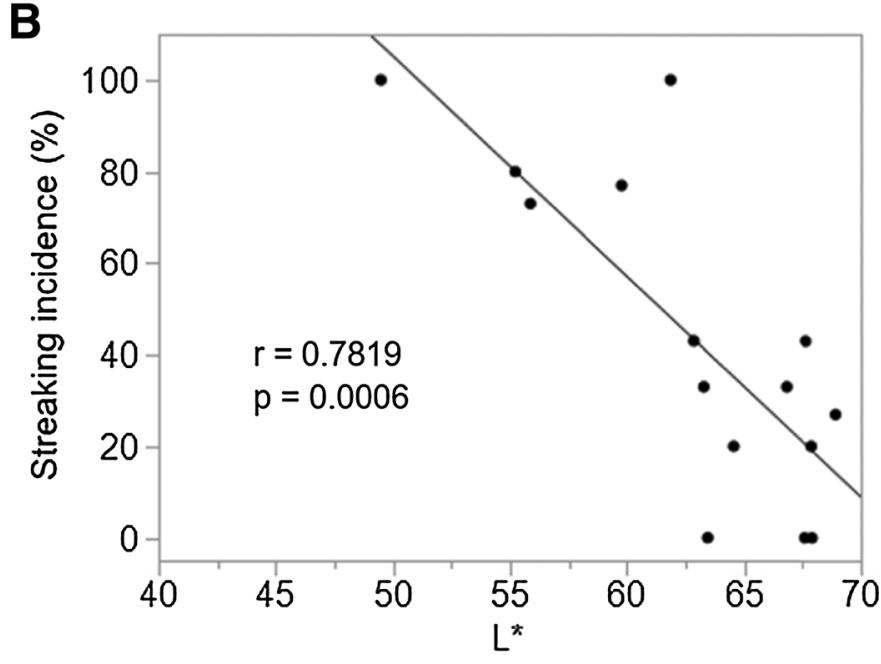

D

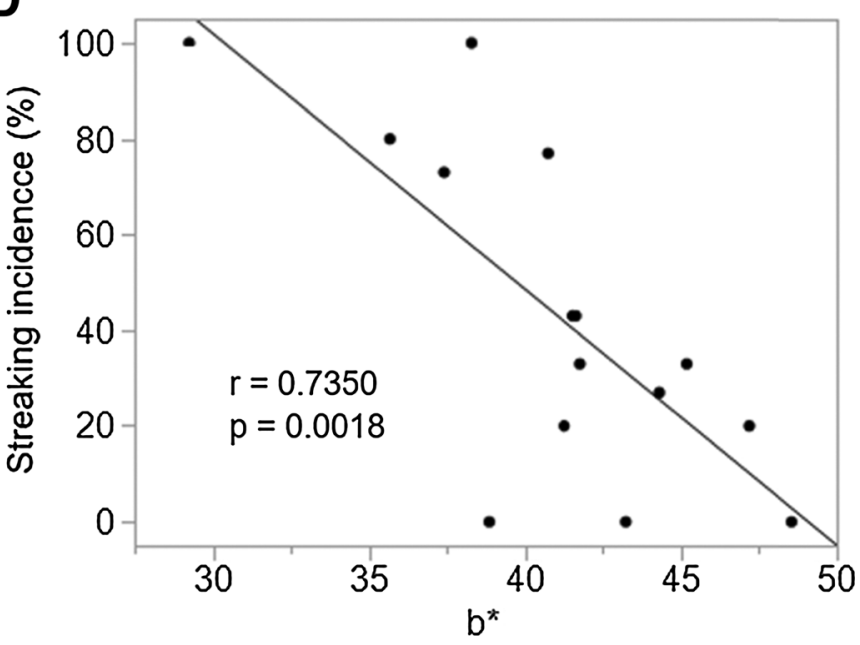

FIGURE 2

Relationship between streaking susceptibility of fruit and light absorbance parameters: $\mathbf{A}, \Delta \mathrm{A}$, difference of absorbance between 670 and $720 \mathrm{~nm} ; \mathbf{B}, \mathrm{L}^{*}$, blush intensity with $-\mathrm{L}^{*}$ (dark) and $+\mathrm{L}^{*}$ (light); C, $\mathbf{a}^{*}$, with -a* (green) and $+\mathrm{a}^{*}$ (red); and D, b* with $-\mathrm{b}^{*}$ (yellow) and $+b^{*}$ (blue). 
hydroxide $\left(\mathrm{NH}_{4} \mathrm{OH}\right)$, which is of low volatility and likely to remain in solution (ATSDR 2004, IUPAC). Generally, $\mathrm{ClO}_{2}$ disassociates into chlorite $\left(\mathrm{ClO}_{2}{ }^{-}\right)$and chlorate $\left(\mathrm{ClO}_{3}{ }^{-}\right)$in aqueous solutions, whereas chloride $\left(\mathrm{Cl}^{-}\right)$is formed additionally at low $\mathrm{pH}$ (Medir and Giralt 1982). The rate of decomposition of $\mathrm{ClO}_{2}$ increases with increasing alkalinity of the aqueous solution (Odeh et al. 2002).

Evaluation of streaking susceptibility during fruit maturation and concurrent measurement of light absorbance parameters confirmed that peach fruit is most susceptible 1 week before harvest while fruit finish is established. This is consistent with earlier findings showing that peach fruit was more susceptible to $\mathrm{ClO}_{2}$ at 1 week prior to commercial maturity compared with 3 weeks under field conditions (Hu et al. 2017). In our study, linear regression suggested that the difference of absorbance $\Delta \mathrm{A}$ and blush $a^{*}$ were good indicators of susceptibility. Both parameters can be measured nondestructively and therefore present a method to determine a cultivar's maturity stage most susceptible to streaking. DA meters are handheld devices already used in fruit production to quickly assess time to harvest. In the case of PSS, the use of DA meters could allow growers to simultaneously approximate time to maturity of peaches in the field and proneness to PSS (Table 4). Then, preventive measures could be undertaken whenever susceptibility and rain coincide.

In summary, PSS affects numerous cultivars, including topselling varieties. Although PSS has been reported in several

\section{TABLE 4}

Difference of absorbance and predicted susceptibility to peach skin streaking

\begin{tabular}{lc}
\hline$\Delta \mathrm{A}$ & Predicted susceptibility $(\%)$ \\
\hline 2.00 & 5 \\
1.92 & 10 \\
1.68 & 25 \\
1.28 & 50 \\
0.88 & 75 \\
0.64 & 90 \\
\hline
\end{tabular}

states, occurrence is concentrated in the southeastern states, where peach production is an essential part of local economies. Despite increasing efforts, particularly in-depth rainwater analysis over several growing seasons and in different locations, the cause of PSS remains unidentified. However, light parameters have been found to indicate susceptibility of peach fruit to PSS.

\section{ACKNOWLEDGMENTS}

The authors thank Jeffrey Hopkins, farm manager of the Musser Fruit Research Center, for his help and advice.

\section{LITERATURE CITED}

Agency for Toxic Substances and Disease Registry. 2004. Medical management guidelines (MMGs) for ammonia. Division of Toxicology, U.S. Department of Health and Human Services. Public Health Service, Atlanta, GA. https://www.atsdr.cdc.gov/mhmi/mmg126.pdf (accessed August 18, 2021).

Bonora, E., Noferini, M., Vidoni, S., and Costa, G. 2013. Modeling of fruit ripening for improving peach homogeneity in planta. Sci. Hort. 159: 166-171.

Frett, T. J., Reighard, G. L., Okie, W. R., and Gasic, K. 2014. Mapping quantitative trait loci associated with blush in peach [Prunus persica (L.) Batsch]. Tree Genet. Genom. 10:367-381.

Gordon, G. 1995. The chemistry and reactions of ozone in our environment. Prog. Nucl. Energy 29:89-86.

Hu, M.-J., Peng, C., Melgar, J. C., and Schnabel, G. 2017. Investigation of potential causes of peach skin streaking. Plant Dis. 101:1601-1605.

International Union of Pure and Applied Chemistry. Ammonium hydroxide. http://sitem.herts.ac.uk/aeru/iupac/Reports/34.htm\#1 (accessed August 18, 2021).

Medir, M., and Giralt, F. 1982. Stability of chlorine dioxide in aqueous solution. Water Res. 16:1370-1382.

Nyasordzi, J., Friedman, H., Schmilovitch, Z., Ignat, T., Weksler, A., Rot., I., and Lurie, S. 2013. Utilizing the $I_{\mathrm{AD}}$ index to determine internal quality attributes of apples at harvest and after storage. Postharvest Biol. Technol. 77:80-86.

Odeh, I. N., Francisco, J. S., and Margerum, D. W. 2002. New pathways for chlorine dioxide decomposition in basic solution. Inorg. Chem. 41: 6500-6506.

Schmitz, L. T., and Schnabel, G. 2019. Infrequent occurrence of peach skin streaking and the role of rainwater attributes on symptom development Plant Dis. 103:2606-2611. 